\title{
Electrochemical Study of Redox Reaction of Various Gold III Chloride Concentrations in Acidic Solution
}

\author{
Afolabi Ayeni, Shafiq Alam*, Georges Kipouros \\ Department of Chemical and Biological Engineering, University of Saskatchewan, Saskatoon, Canada \\ Email: *shafiq.alam@usask.ca
}

How to cite this paper: Ayeni, A., Alam, S. and Kipouros, G. (2018) Electrochemical Study of Redox Reaction of Various Gold III Chloride Concentrations in Acidic Solution. Journal of Materials Science and Chemical Engineering, 6, 80-89.

https://doi.org/10.4236/msce.2018.61009

Received: December 13, 2017

Accepted: January 26, 2018

Published: January 29, 2018

Copyright $\odot 2018$ by authors and Scientific Research Publishing Inc. This work is licensed under the Creative Commons Attribution International License (CC BY 4.0).

http://creativecommons.org/licenses/by/4.0/

\begin{abstract}
The redox reaction of gold III chloride in acid solutions has been electrochemically investigated using a cyclic voltammetry technique. This paper emphasizes the current and potential sites at which gold III chloride is reduced in hydrochloric acid that is vital to electrochemical evaluation of gold recovery. The solutions were prepared by reacting $\mathrm{HCl}$ with $\mathrm{AuCl}_{3}$ in various concentrations thus 30 and $60 \mathrm{mg} / \mathrm{L} \mathrm{AuCl}_{3}$ in 0.1 and $0.5 \mathrm{M} \mathrm{HCl}$, respectively. Solutions of 0.1 and $0.5 \mathrm{M} \mathrm{HCl}$ containing 0,30 and $60 \mathrm{mg} / \mathrm{L} \mathrm{AuCl}_{3}$, respectively were tested for possible reduction and oxidation reactions by cyclic voltammogram experiment using a glassy carbon, a saturated calomel and a platinum wire mesh as working, reference and counter electrodes, respectively. The results showed no peak in the case of the absence of $\mathrm{AuCl}_{3}$ in the solutions, but appreciable cathodic and anodic peaks for the reduction and oxidation of various concentrations of $\mathrm{AuCl}_{3}$ in acid solutions. The reaction between $\mathrm{AuCl}_{3}$ and $\mathrm{HCl}$ was found to be reversible because the ratio of oxidation peak current and reduction peak current was 1 . The concentration of $\mathrm{AuCl}_{4}^{-}$on the surface of the working electrode at the reduction site for each $\mathrm{AuCl}_{3}$ concentration using Nernst equation was $1.22 \times 10^{9} \mathrm{ppm}$ and $2.44 \times 10^{9}$ $\mathrm{ppm}$. The reduction potentials were independent of concentration, while the current was highly dependent of concentration.
\end{abstract}

\section{Keywords}

Redox Reaction, Cyclic Voltammetry, Nernst Equation, Gold, Chloride

\section{Introduction}

The demand for gold in the global market has jolted researchers into gold re- 
covery methods from either a lean ore or waste products of consumer electronics (urban mining). Sometimes, synthetic solutions are used to study the extraction of gold in a preliminary laboratory experiment. Gold III chloride is the auric salts commonly used to achieve this purpose [1]. Hydrochloric acid has been the popular leachant for precious metals from secondary sources [2]. Hence, in this study, solutions of gold III chloride in $\mathrm{HCl}$ were prepared to investigate reversible and redox reactions using a cyclic voltammetry technique.

Few studies have been carried out on the electrochemical reduction to metal, such as the electrochemical reduction of silver from iodide solutions [3]. Fourcade and Tzedakis [3] used a potentiostat as the electrochemical apparatus with a silver disk working electrode, a saturated calomel reference electrode and a platinum counter electrode to measure all the electrode potentials during the adsorption experiments. Tao et al. [4] reported scanning tunneling microscopy (STM) and electrochemical study of the interplay between redox properties, adsorption, and self-assembly processes of porphins on Au surfaces.

The cyclic voltammetry technique is generally used to study the electrochemical properties of an analyte in solution [5] [6] [7]. The theory of voltammetric methods is based on the solution of the Nernst Equation (1). Voltammetry is a method in which information about an analyte is obtained by measuring the current generated as the applied potential to the working electrode is varied. Potential is measured between the working electrode and the reference electrode, while current is measured between the working and the counter electrode [8] [9]. The Nernst Equation is expressed in terms of potential at the working electrode.

$$
E=E^{0}-\frac{R T}{n F} \ln Q
$$

where, $E=$ measured potential, $E^{0}=$ standard electrode potential, $R=$ gas constant, $T=$ temperature $\left({ }^{\circ} \mathrm{K}\right), Q=$ reaction quotient, $n=$ number of electrons exchanged, and $F=$ Faraday's constant.

The redox reaction and half-cell reaction of gold III chloride in $\mathrm{HCl}$ are represented in reactions $\mathrm{R} 1$ and $\mathrm{R} 2$ respectively thus,

$$
\mathrm{AuCl}_{3}+\mathrm{HCl} \rightarrow\left[\mathrm{AuCl}_{4}\right]^{-}+\mathrm{H}^{+}
$$

For half-cell reaction,

$$
\mathrm{AuCl}_{3}+e^{-} \rightarrow \mathrm{AuC}_{4}^{-}
$$

The result from the experiment showed no reasonable cathodic or anodic peak for hydrochloric acid solution without the presence of gold III chloride, while peaks were observed during the measurement of various concentrations of the gold III chloride in hydrochloric acid solution. It could be deduced from the experiment the reaction of gold III chloride with $\mathrm{HCl}$ is a redox and reversible reaction.

The objective of this work was to investigate the reaction processes in gold III chloride acid solution using cyclic voltammetry. 


\section{Experimental}

\subsection{Materials and Instrumentations}

Glassware, analytical grade hydrochloric acid, gold (III) chloride, and de-ionized water were used for the preparation of the solutions. The electrochemical equipment consisted of a PAR 283 Potentiostat/Galvanostat (PS/GS) and a Solartron 1260 Frequency response analyzer, Glassy carbon electrode was used as working electrode (WE), a platinum mesh served as counter electrode (CE), while a saturated calomel electrode (SCE) was the reference electrode (RE).

\subsection{Experimental Procedure}

\subsubsection{Preparation of Solution}

Solutions of $30 \mathrm{ppm}$ and $60 \mathrm{ppm}$ of $\mathrm{AuCl}_{3}$ in $200 \mathrm{~mL}$ of 0.1 and $0.5 \mathrm{M} \mathrm{HCl}$ were prepared. The reaction between $\mathrm{AuCl}_{3}$ and $\mathrm{HCl}$ is a redox as shown in $\mathrm{R} 1 . \mathrm{AuCl}_{3}$ was reduced to $\mathrm{AuCl}_{4}^{-}$and $\mathrm{HCl}$ was oxidized to $\mathrm{H}^{+}$. This redox reaction was electrochemically measured by subjecting the gold chloride solution to cyclic voltammogram experiment, in which the cathodic and anodic current peaks were determined relative to applied potentials. This was achieved with a core driven software PAR 283 Potentiostat/Galvanostat (PG/GS) and a Z-plot driven solartron instrument [3]. Cleaning of the electrodes was done prior to the experiment, for the purpose of revealing the surface of the electrodes which might have been covered by impurities, and conditioned them for the experiment as reported by Feng et al., [10]. The $0.5 \mathrm{M} \mathrm{HCl}$ was prepared, and the electrodes were immersed in the diluted solution. The electrodes were then connected to the Potentiostat which was set at cyclic voltammogram experiment mode for cleaning. The vertex potential 1 and 2 were set at -0.25 and $1.25 \mathrm{~V}$ respectively at a scan rate of $5.0 \mathrm{mV} / \mathrm{s}$. The cleaning was done for $1 \mathrm{~h}$.

Subsequently, about $100 \mathrm{~mL}$ of $30 \mathrm{ppm} \mathrm{AuCl}_{3}$ (in $0.1 \mathrm{M} \mathrm{HCl}$ ) was poured into a $250 \mathrm{~mL}$ beaker. The electrodes were immersed into the solution and connected with connecting cables to the Instrument accordingly.

\subsubsection{Cyclic Voltammetry Measurement}

The cyclic voltammogram experiment was performed with a PAR potentiostat/galvanostat. The schematic of the setup is as shown in Figure 1. The applied potential was set between $-0.25 \mathrm{~V}$ and $1.25 \mathrm{~V}$. The scan rate was set at $5 \mathrm{mV} / \mathrm{s}$, and the No. of cycles was maintained at $1 \mathrm{mV} /$ point. During the measurement, the scanning of the potential was from -0.25 to 1.25 , and then back to -0.25 at a rate of $5 \mathrm{mV} / \mathrm{s}$ for 1 cycle. This procedure was performed on all the prepared solutions and the measurement of peaks was recorded via the plot of current density as a function of the potential. The experiment was carried out at a room temperature of $25^{\circ} \mathrm{C}$.

\section{Results and Discussion}

The experimental results are depicted in Figures 1-6. The system moved through the various dynamic regime (start-finish), and the oxidation and reduction 


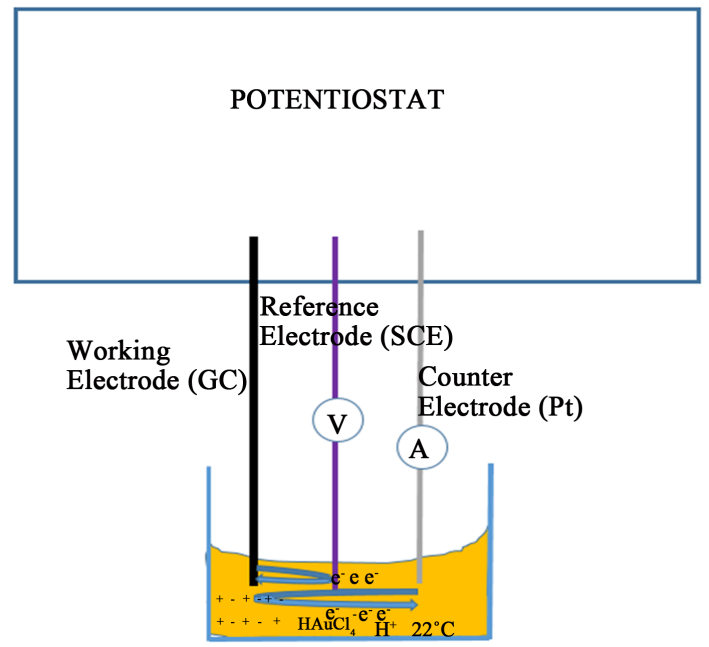

Figure 1. Cyclic voltammetry measurement of $30 \mathrm{ppm} \mathrm{AuCl}_{3}$ in $0.1 \mathrm{M} \mathrm{HCl}$ at room temperature $\left(25^{\circ} \mathrm{C}\right)$.

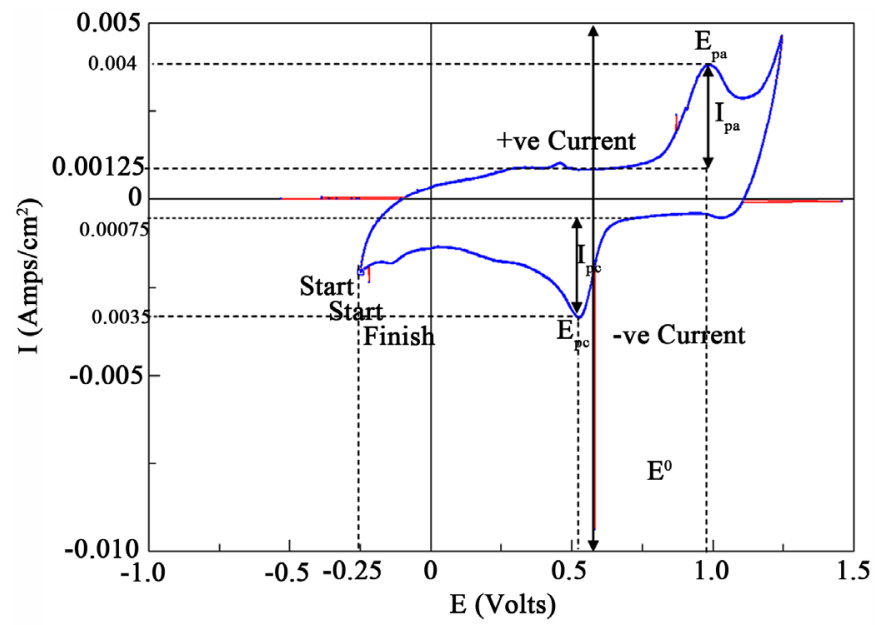

Figure 2. Cyclic voltammetry measurement of $60 \mathrm{ppm} \mathrm{AuCl}_{3}$ in $0.1 \mathrm{M} \mathrm{HCl}$ solution at room temperature $\left(25^{\circ} \mathrm{C}\right)$.

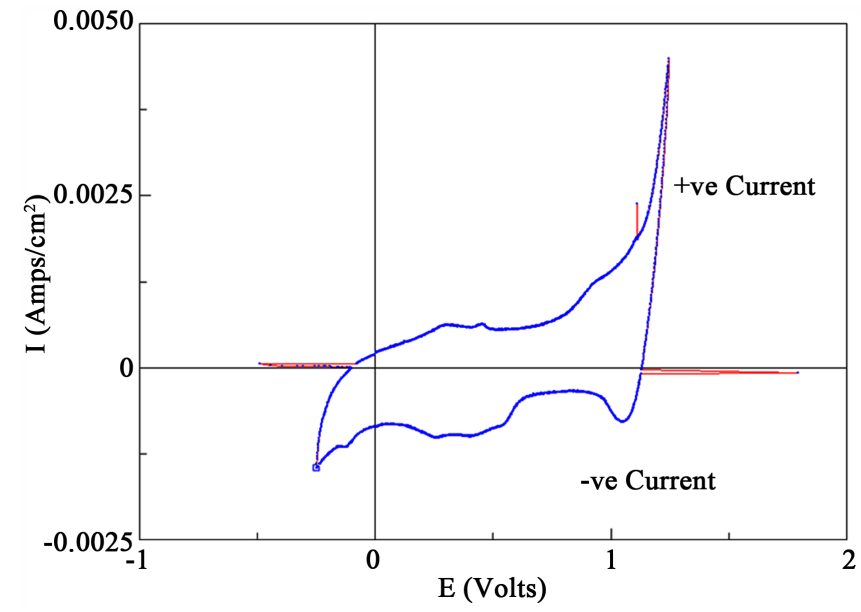

Figure 3. Cyclic voltammetry measurement of $0 \mathrm{ppm} \mathrm{AuCl}_{3}$ in $0.1 \mathrm{M} \mathrm{HCl}$ solution at room temperature $\left(25^{\circ} \mathrm{C}\right)$. 


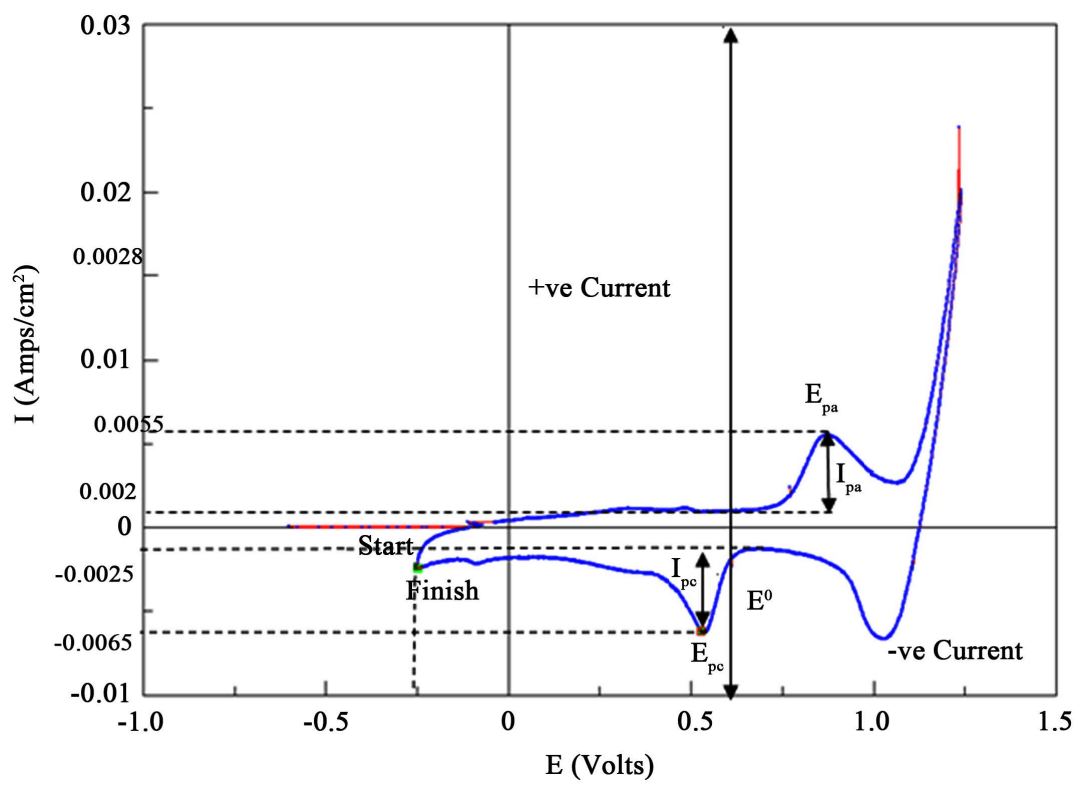

Figure 4. Cyclic voltammetry measurement of $30 \mathrm{ppm} \mathrm{AuCl}_{3}$ in $0.5 \mathrm{M} \mathrm{HCl}$ solution at room temperature $\left(25^{\circ} \mathrm{C}\right)$.

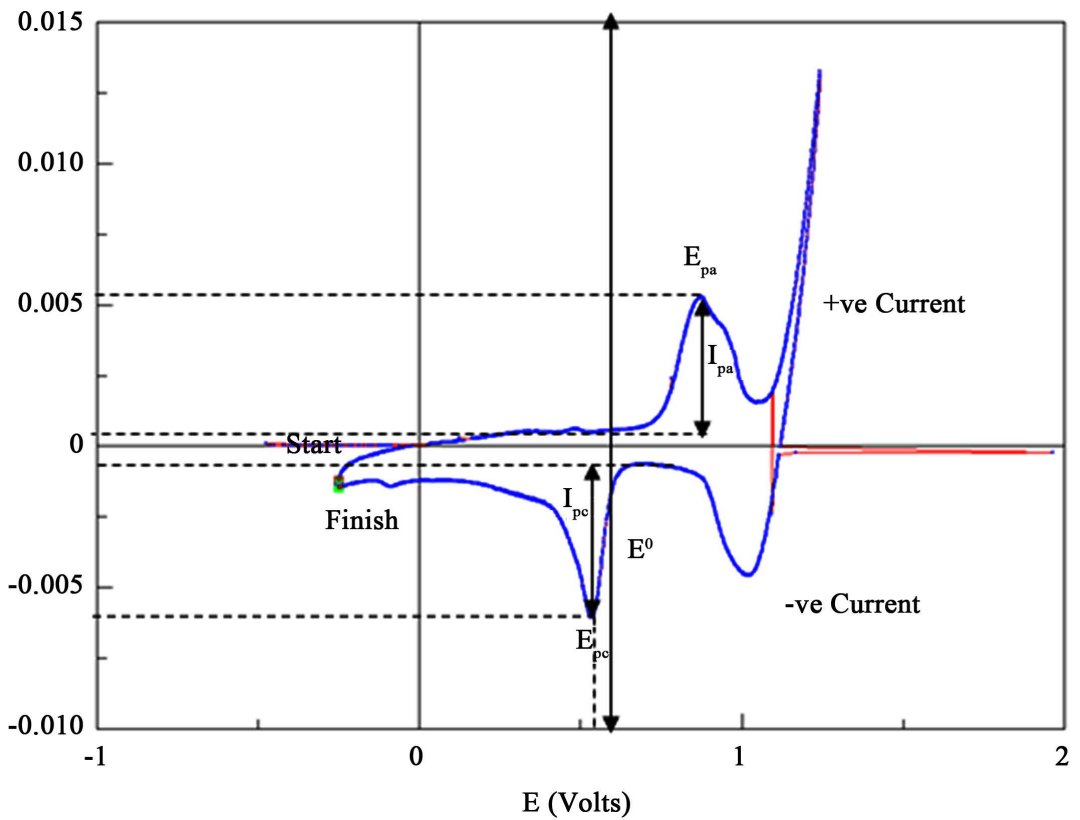

Figure 5. Cyclic voltammetry measurement of $60 \mathrm{ppm} \mathrm{AuCl}_{3}$ in $0.5 \mathrm{M} \mathrm{HCl}$ solution at room temperature $\left(25^{\circ} \mathrm{C}\right)$.

peaks could be observed through the voltammogram. The figures represent the current generated by applied cyclic potentials on $30 \mathrm{ppm}, 60 \mathrm{ppm}, 0 \mathrm{ppm} \mathrm{AuCl}_{3}$ in 0.1 and $0.5 \mathrm{M} \mathrm{HCl}$, respectively. Where, $E_{p a}$ and $E_{p c}$ were oxidation and reduction potential peaks, respectively, and $I_{p a}$ and $I_{p c}$ were the corresponding current at the peak of oxidation and reduction in that order.There are reports on the formation of these asymmetry peaks during voltammetric measurements [3] [4] [11]. 


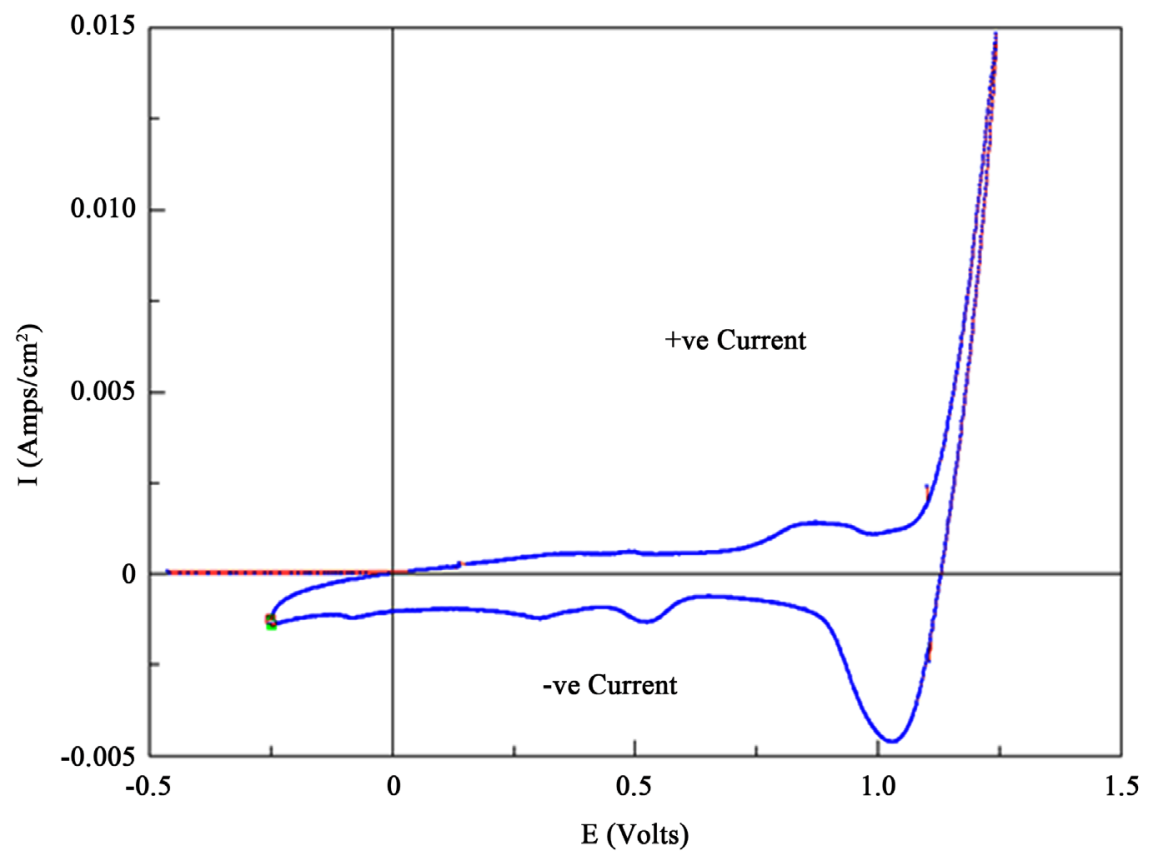

Figure 6. Cyclic voltammetry measurement of $0 \mathrm{ppm} \mathrm{AuCl}_{3}$ in $0.5 \mathrm{M} \mathrm{HCl}$ solution at room temperature $\left(25^{\circ} \mathrm{C}\right)$.

In Figure 1, oxidation peak was reached at about $1 \mathrm{~V}\left(E_{p a}\right)$, and $0.0028 \mathrm{~A} / \mathrm{cm}^{2}$ current density $\left(I_{p a}\right)$ was generated. At this point the $\mathrm{HCl}$ was oxidized completely to $\mathrm{H}^{+}$. On the other hand, the complete reduction of $\mathrm{AuCl}_{3}$ to $\mathrm{AuCl}_{4}^{-}$ was achieved at a potential $E_{p c}$ and current $I_{p c}$ of $0.55 \mathrm{~V}$ and $0.0028 \mathrm{~A} / \mathrm{cm}^{2}$, respectively. Khunathai et al. reported the standard reduction potential $E^{0}$ of $\mathrm{AuCl}_{4}^{-}$to be $1.0 \mathrm{~V}$ [11]. The Nernst equation (1) was employed to determine the concentration of reduced auric chloride ion $\left(\mathrm{AuCl}_{4}^{-}\right)$at the surface of the working electrode in $30 \mathrm{ppm}$ solution, thus:

$$
E=E^{0}-\frac{R T}{n F} \ln Q
$$

From the half-reaction depicted in reaction R2,

$$
\begin{aligned}
\ln Q & =\ln \frac{\text { concentration of } \mathrm{AuCl}_{4}^{-}}{\text {concentration of } \mathrm{AuCl}_{3}}=\left(E^{0}-E\right) \frac{n F}{R T} \\
& =(1-0.55) \times \frac{1 \times 96500}{8.314 \times(273+25)}=17.52
\end{aligned}
$$

Concentration of $\mathrm{AuCl}_{4}^{-}=30 \times \mathrm{e}^{17.52}=1.22 \times 10^{9} \mathrm{ppm}$

For a reversible reaction [6],

$$
I_{p c}: I_{p a}=1
$$

In Figure 1, $I_{p c}=0.0035-0.00075=0.00275$

$$
I_{p a}=0.004-0.00125=0.00275 .
$$

Hence, $I_{p c}: I_{p a}=0.00275: 0.00275=1$. 
From this experiment, $30 \mathrm{ppm}$ of $\mathrm{AuCl}_{3}$ would be reduced to $\mathrm{AuCl}_{4}^{-}$at the reduction peak on the surface of the working electrode at a concentration of 1.22 $\times 10^{9} \mathrm{ppm}$. The reaction was also a reversible reaction, considering the ratio of $I_{p c}$ to $I_{p a}$ which was found to be 1 [6].

Figure 2 shows voltammetry measurement of $60 \mathrm{ppm} \mathrm{AuCl}_{3}$ in $0.1 \mathrm{M} \mathrm{HCl}$ solution, with the $E_{p c}$ and $E_{p a}$ obtained at $0.55 \mathrm{~V}$ and $1.23 \mathrm{~V}$, respectively. The corresponding cathodic and anodic peak current density $\left(I_{p c}\right.$ and $\left.I_{p a}\right)$ were 0.0022 and $0.0024 \mathrm{~A} / \mathrm{cm}^{2}$. From Equations (1) and (2) respectively, the concentration of the $\mathrm{AuCl}_{4}^{-}$at reduction peak on the surface of the electrode was $2.44 \times 10^{9}$ $\mathrm{ppm}$, and the ratio of $I_{p c}$ to $I_{p a}$ was 1 . Hence, the reaction was also a reversible one.

Figure 3 depicts the voltammetry measurement of $0.1 \mathrm{M} \mathrm{HCl}$ without $\mathrm{AuCl}_{3}$ $\left(0 \mathrm{ppm} \mathrm{AuCl}_{3}\right)$, no peak was feasible either at the oxidation zone or reduction zone. This confirmed electrochemically, that the reaction between $\mathrm{HCl}$ and water was not a redox reaction but a dissociation

$$
\mathrm{HCl}+\mathrm{H}_{2} \mathrm{O} \rightarrow \mathrm{H}_{3} \mathrm{O}^{+}+\mathrm{Cl}^{-}
$$

Figure 4 and Figure 5 represented the higher concentration of $\mathrm{AuCl}_{3}$ and $\mathrm{HCl}$, however the values of $E_{p c}$ was the same as that of Figure 1 and Figure 2 $(0.55 \mathrm{~V})$, indicating evidence that the standard potential and reduction potential peaks did not change with concentration. The reduction peak current varied with concentration as shown in Figure 1 and Figure 4 was -0.0035 and -0.0065 $\mathrm{A} / \mathrm{cm}^{2}$, respectively. Figure 6, just like Figure 3, had no peak because it was not a redox reaction.

\section{Summary of Cyclic Voltammetry (CV) Curves for Various Concentrations}

The form of CV curves as depicted in Figure 7 are like those published in various literature under similar experimental conditions [11] [12] [13] [14] [15].

\section{Conclusion}

The redox reaction of $\mathrm{AuCl}_{3}$ in $\mathrm{HCl}$ solution of various concentrations has been electrochemically studied using a cyclic voltammetry technique. The concentration of the reduced $\mathrm{AuCl}_{4}^{-}$ion was determined using the Nernst equation. The results showed that anodic and cathodic peaks were present in the solution containing $\mathrm{AuCl}_{3}$ of various concentrations, while no peaks were generated in $\mathrm{HCl}$ solution in the absence of $\mathrm{AuCl}_{3}$. The measured $E_{p c}$ in the tested solutions was the same showing evidence that the reduction potentials were independent of the concentration. However, the reduction current varied with the concentration of solution, affirming the dependency of current on concentration. This study has interesting implication to determine the electrochemical parameters of gold reduction during leaching and adsorption processes with more accurate results obtained for specific process. 


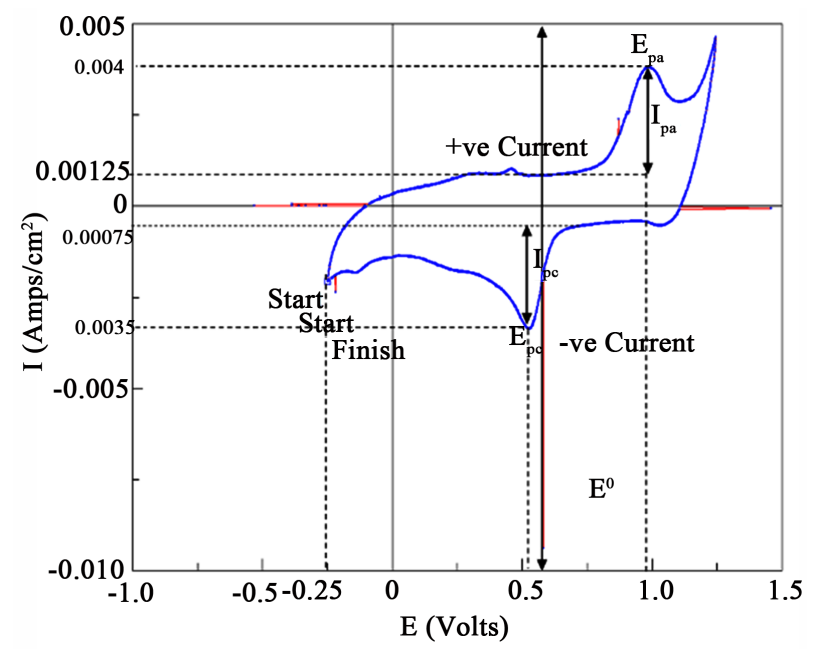

(a)

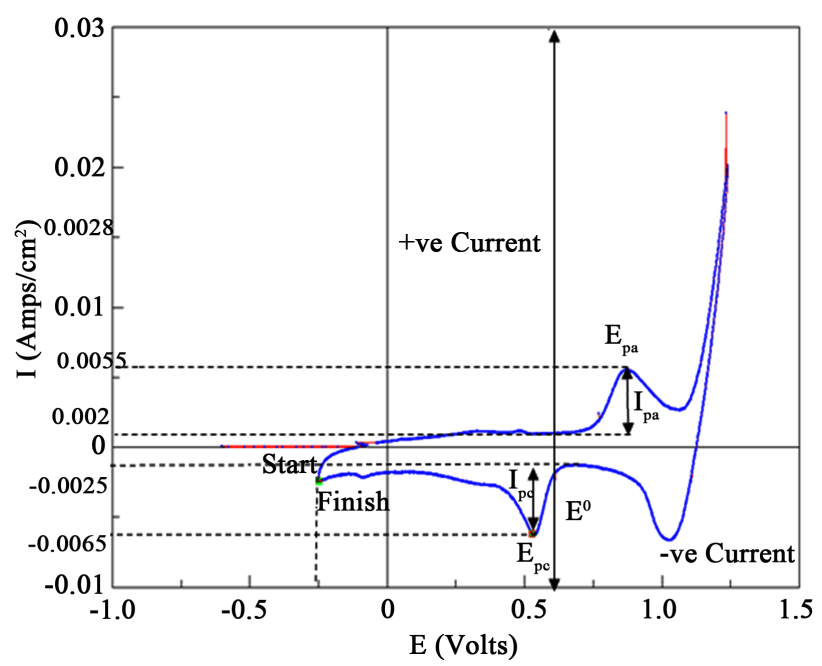

(c)

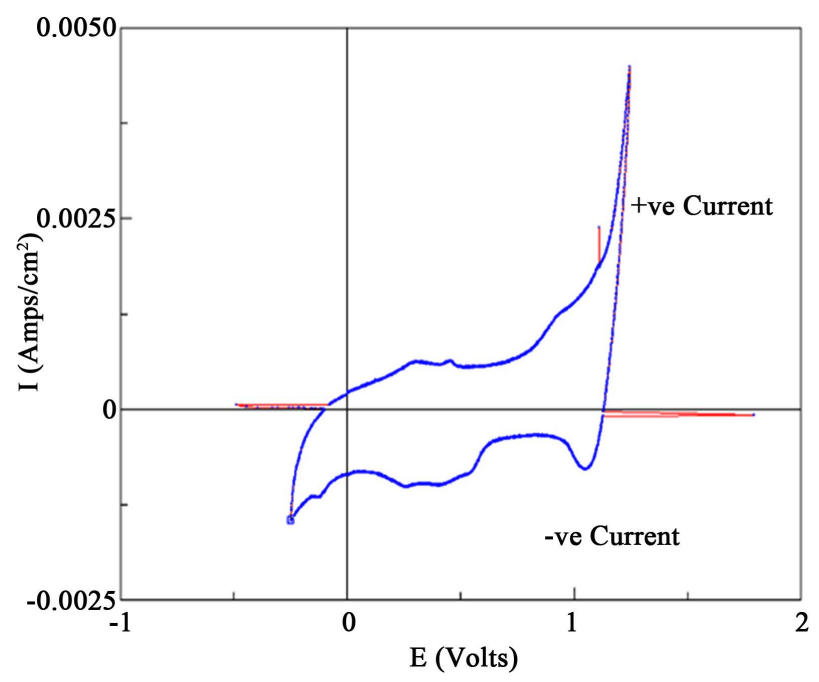

(e)

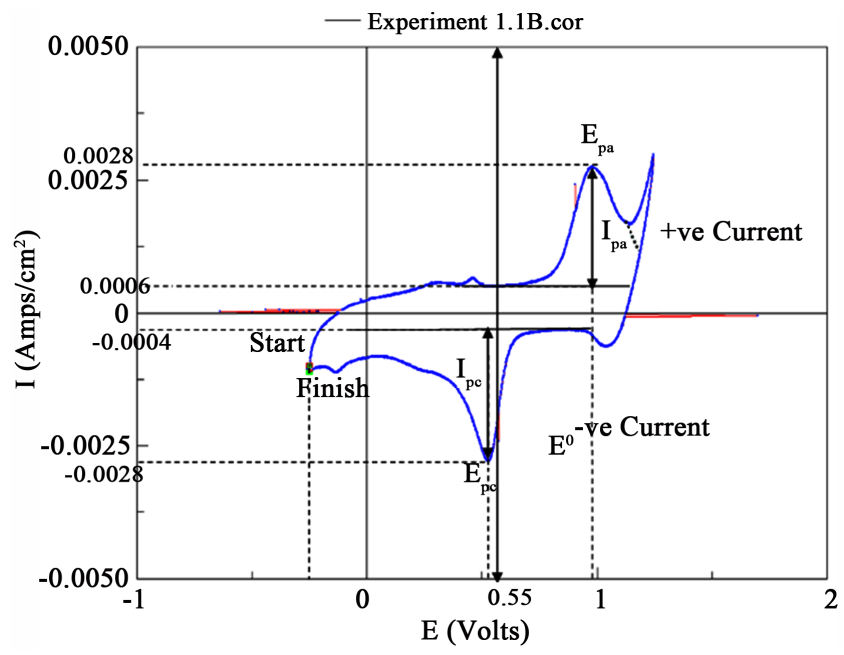

(b)

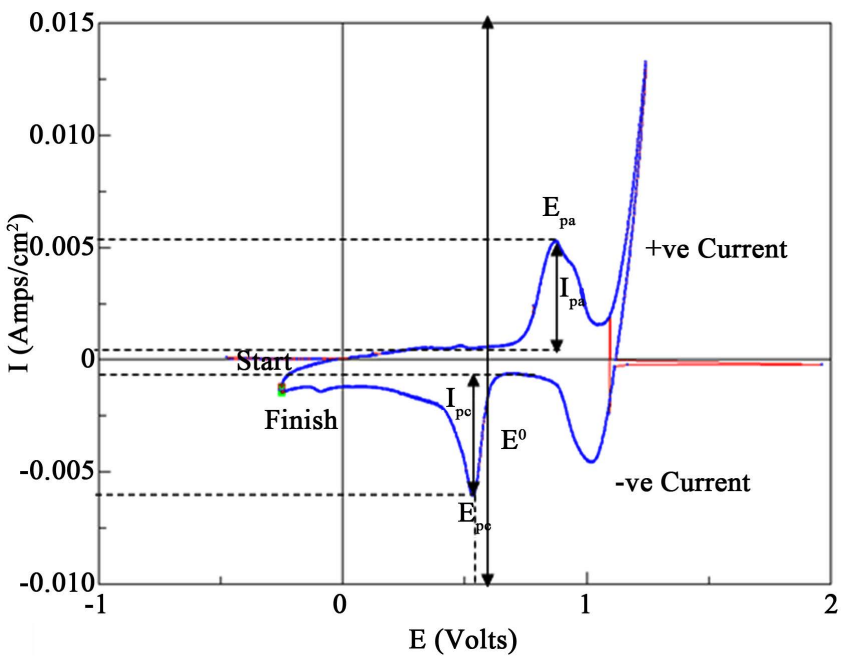

(d)

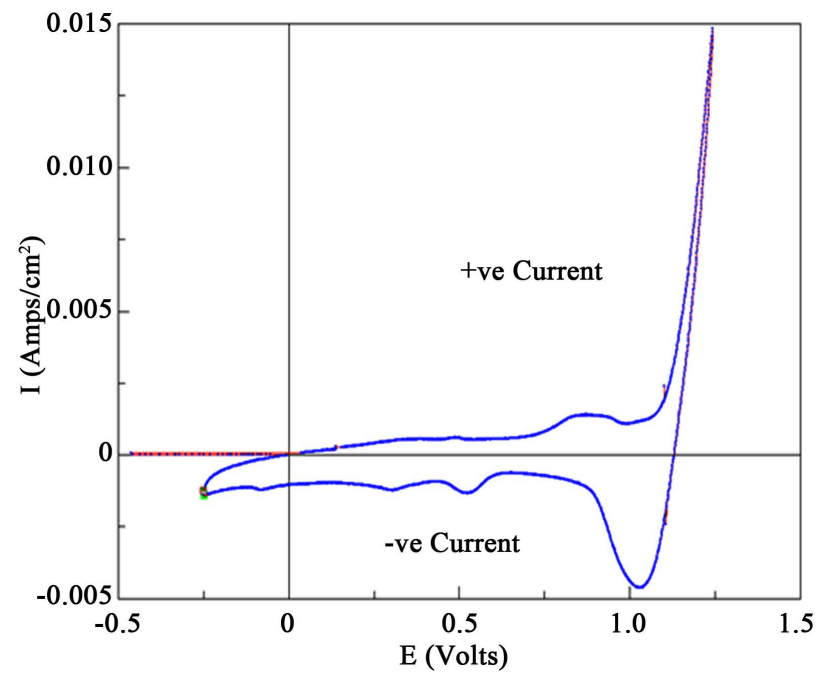

(f)

Figure 7. Cyclic voltammetry curves of (a) $30 \mathrm{ppm} \mathrm{AuCl}_{3}$ in $0.1 \mathrm{M} \mathrm{HCl}$; (b) $60 \mathrm{ppm} \mathrm{AuCl}$ in $0.1 \mathrm{M} \mathrm{HCl}$; (c) $30 \mathrm{ppm} \mathrm{AuCl} \mathrm{pin}_{3} 0.5$ $\mathrm{M} \mathrm{HCl}$; (d) $60 \mathrm{ppm} \mathrm{AuCl}$ in $0.5 \mathrm{M} \mathrm{HCl}$; (e) $0 \mathrm{ppm} \mathrm{AuCl}$ in $0.1 \mathrm{M} \mathrm{HCl}$ and (f) $0 \mathrm{ppm} \mathrm{AuCl}_{3}$ in $0.5 \mathrm{M} \mathrm{HCl}$ at room temperature. 


\section{Acknowledgements}

The equipment was calibrated with the support of Prince Yuan Ding (Dalhousie University, Halifax) and Will Judge (University of Toronto).

\section{References}

[1] Barakat, M.A. and Mahmoud, M.H.H. (2004) Recovery of Platinum from Spent Catalyst. Hydrometallurgy, 72, 179-184. https://doi.org/10.1016/S0304-386X(03)00141-5

[2] Adhikari, B.B., Gurung, M., Alam, S., Tolnai, B. and Inoue, K. (2013) Kraft Mill Lignin-A Potential Source of Bio-Adsorbents for Gold Recovery from Acidic Chloride Solution. Chemical Engineering Journal, 231, 190-197. https://doi.org/10.1016/j.cej.2013.07.016

[3] Fourcade, F. and Tzedakis, T. (2000) Study of the Mechanism of the Electrochemical Deposition of Silver from an Aqueous Silver Iodide Suspension. Journal of Electroanalytical Chemistry, 493, 20-27. https://doi.org/10.1016/S0022-0728(00)00318-1

[4] Ye, T., He, Y. and Bourguet, E. (2006) Adsorption and Electrochemical Activity: An In-Situ Electrochemical Scanning Tunneling Microscopy Study of Electrode Reactions and Potential-Induced Adsorption of Porphyrins. Journal of Physical Chemistry, 110, 6141-6147. https://doi.org/10.1021/jp053358w

[5] Bard, A.J. and Faulkner, L.R. (2000) Electrochemical Methods, Fundamentals and Applications. 2nd Edition, Wiley, Hoboken.

[6] Nicholson, R.S. and Irving, S. (1964) Theory of Stationary Electrode Polarography: Single Scan and Cyclic Methods Applied to Reversible, Irreversible, and Kinetic Systems. Analytical Chemistry, 36, 706-723. https://doi.org/10.1021/ac60210a007

[7] Heinze, J. (1984) Cyclic Voltammetry— “Electrochemical Spectroscopy”: New Analytical Methods. AngewandteChemie International Edition, 23, 831-847.

https://doi.org/10.1002/anie.198408313

[8] Kissinger, P. and William, R.H. (1996) Laboratory Techniques in Electroanalytical Chemistry. 2nd Edition, Revised and Expanded, CRC, Boca Raton.

[9] Zoski, C.G. (2007) Handbook of Electrochemistry. Elsevier Science, Amsterdam.

[10] Feng, J., Gao, Q., Lv, X. and Epstein, I.R. (2008) Dynamic Complexity in the Electrochemical Oxidation of Thiourea. Journal of Physical Chemistry, 112, 6578-6585. https://doi.org/10.1021/jp802002k

[11] Khunathai, K., Matsueda, M., Biswas, B.K., Kawakita, H., Ohto, K., Harada, H., Inoue, K., Funaoka, M. and Alam, S. (2011) Adsorption Behavior of Lignophenol Compounds and Their Dimethylamine Derivatives Prepared from Rice and Wheat Straws for Precious Metal Ion. Journal of Chemical Engineering of Japan, 44, 781787.

[12] Ahmed, M.I., Aziz, A.M., Helal, A. and Sheikh, M.N. (2016) Direct Electrodeposition of Nanogold on Gallium-Doped Zinc Oxide by Cyclic Voltammetry and Constant-Potential Techniques: Application to Electro-Oxidation of Sulfite. Journal of the Electrochemical Society, 163, D277-D281. https://doi.org/10.1149/2.0461607jes

[13] Naumowicz, M. (2016) Cyclic Voltammetry and Chloroamperometry Techniques in Description of the Surface-Active Phospholipid Bilayer Relative to Acid-Base Equilibria. Journal of the Electrochemical Society, 163, H750-H756. https://doi.org/10.1149/2.0301609jes

[14] Lee, J.B. and Kim, S.W. (2007) Semiconducting Properties of Passive Films Formed on Fe-Cr Alloys Using Capacitance Measurements and Cyclic Voltammetry Tech- 
niques. Materials Chemistry and Physics, 104, 98-104.

https://doi.org/10.1016/j.matchemphys.2007.02.089

[15] Sullivan, A.M. and Kohl, P.A. (1997) Electrochemical Study of the Gold Thiosulfate Reduction. Journal of the Electrochemical Society, 144, 1686-1690.

https://doi.org/10.1149/1.1837660 